\title{
Mechanism of the Manganese-Pincer Catalyzed Acceptorless Dehydrogenative Coupling of Nitriles and Alcohols
}

\author{
Jesús A. Luque-Urrutia, ${ }^{\ddagger}$ Miquel Solà, ${ }^{\ddagger, *}$ David Milstein, ${ }^{\S, *}$ and Albert Poater ${ }^{\ddagger, *}$ \\ ‡Institut de Química Computacional i Catàlisi and Departament de Química, Universitat de Girona, C/ Maria Aurèlia Capmany, \\ 69, 17003 Girona, Catalonia, Spain
}

\$Department of Organic Chemistry, The Weizmann Institute of Science, Rehovot, 7610o, Israel

KEYWORDS: manganese, acrylonitrile, acceptorless dehydrogenative coupling, pincer ligand

Supporting Information Placeholder

\begin{abstract}
A recent study showed that a Mn-pincer could catalyze the acceptorless dehydrogenative coupling of nitriles and alcohols to yield acrylonitriles. The reaction mechanism proposed in that work contained some intermediates that, in most of the cases, were not characterized. Moreover, one of the intermediates involved a charged separation, which is unlikely in apolar solvents. To clarify the reaction mechanism of this critical reaction, we decided to perform a DFT study. Our results prove the existence of a cooperative effect of the metal and the ligand in several steps of the catalytic cycle. We also find the presence of several equilibria between isomeric intermediates where water, or the same alcohol reagent, take part in assisting the proton transfer. Furthermore, we have analyzed the charge separated structure proposed experimentally and have found a nearly pure covalent bond between the two expected charged moieties. Finally, the Knoevenagel condensation step that generates the acrylonitrile is found to be the rate-determining step.
\end{abstract}

\section{INTRODUCTION}

Currently being researched by many authors, acrylonitriles are known to be a worthwhile resource in synthesis, including the formation of benzonitriles ${ }^{1}$ and pyrroles $^{2}$ used as a treatment for malaria. ${ }^{3}$ The SOHIO process, ${ }^{4}$ which consists of the catalytic ammoxidation of propylene, is used to produce them on an industrial level. Another recognized way of producing acrylonitriles is to form a $\mathrm{C}=\mathrm{C}$ bond using the Knoevenagel condensation. 5 This reaction involves the nucleophilic attack of an activated carbon, located between two electron withdrawing groups, on a carbonyl, a ketone or an aldehyde.

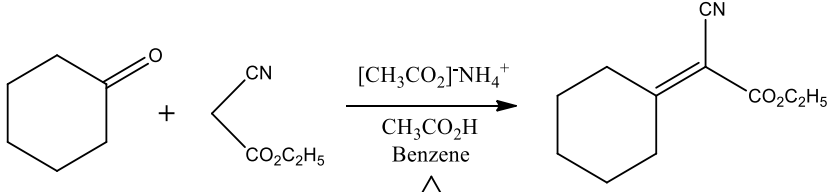

Scheme 1. Knoevenagel condensation for the formation of unsaturated acrylonitriles.
While this is a widely-used synthetic strategy for many applications, ${ }^{6}$ researchers nowadays are aiming to produce it using new methodologies involving less waste, greater productivity, and energy efficiency gain. ${ }^{7}$ One of these approaches to produce acrylonitriles is the catalytic dehydrogenative cross-coupling reaction $(\mathrm{CDC}){ }^{8}$ This procedure requires a sacrificial molecule to accept the liberated hydrogen atoms, thus generating stoichiometric amounts of waste where, ideally, waste should not be generated. To reduce this problem, an upgrade in the mechanism that involves the formation of $\mathrm{H}_{2}$ instead of the hydrogenation of a sacrificial molecule, the so-called acceptorless dehydrogenative coupling $(\mathrm{ADC})^{9}$ reaction, was developed. ${ }^{10}$ In this new procedure that significantly reduces waste, the formation of $\mathrm{H}_{2}$ creates the possibility to synchronize the acrylonitrile synthesis with the controlled production of $\mathrm{H}_{2}$ as a viable energy source. ${ }^{11}$ A problem with this approach is, however, that it usually requires noble transition metal complexes, such as iridium or rhodium, ${ }^{12}$ which are scarce and costly compared to earth-abundant metals like iron, cobalt or manganese. ${ }^{13}$ In 2017, an experimental study by one of us (shown in Scheme 2) reported the (for any catalyst) unprecedented efficient $\alpha$-olefination of nitriles by ADC of alcohols and nitriles, catalyzed by the recently-developed Mn pincer catalyst (1, see Figure 1). ${ }^{14}$

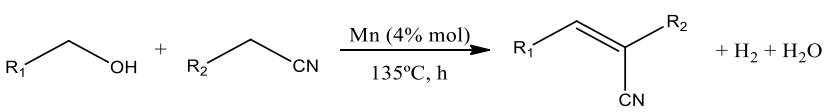

Scheme 2. Catalytic acceptorless dehydrogenative coupling reaction reported by Milstein et al. ${ }^{14}$

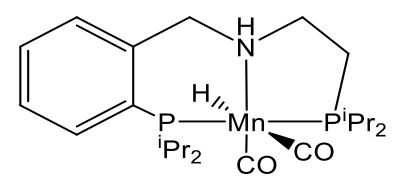

Figure 1. Mn catalyst $\mathbf{1}$ for acceptorless dehydrogenative coupling as reported by Milstein and coworkers. ${ }^{14}$ 
This work used various alcohols and nitriles as starting materials and compared the catalytic activity of $\mathbf{1}$ with that of other recently-reported metal pincer catalysts. ${ }^{15}$ They found that using their Mn catalyst resulted in conversions of up to $>99 \%$ and yielded up to $91 \%$ (see Scheme 3 ).

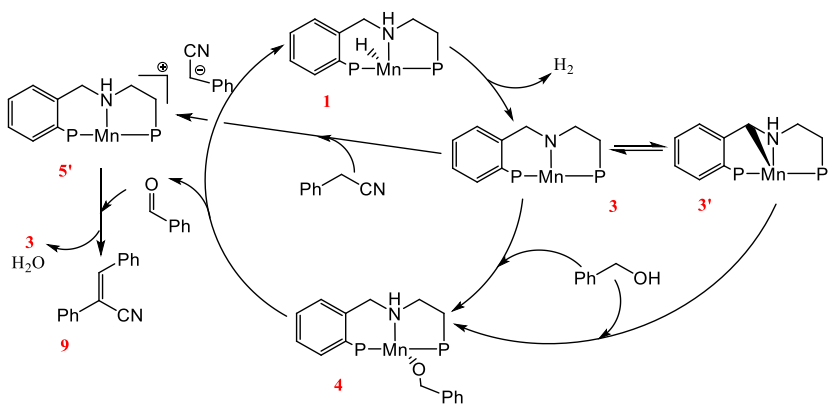

Scheme 3. Proposed mechanism by Milstein et al. of acceptorless dehydrogenative coupling of nitriles with alcohols. We have removed both the carbonyl ligands coordinated to $\mathrm{Mn}$ and ${ }^{\mathrm{P}} \mathrm{Pr}$ groups on the phosphorous atoms for the sake of clarity. ${ }^{14}$
The Mn catalyst represents a more promising possibility in the field of ADC and acrylonitrile synthesis. The production of molecular hydrogen and water as by-products is but one of the key reasons behind the importance of this catalysis. As we believe that this catalyst is a ground-breaking development in its field, here we unravel the whole reaction mechanism using Density Functional Theory (DFT) calculations. We start from the proposed reaction pathway, as shown in Scheme 3. Our primary goal is to better understand the recent experiments by Milstein and coworkers that provide substituted acrylonitrile synthesis by coupling alcohols and nitriles using a manganese pincer complex under mild reaction conditions, ${ }^{14}$ i.e., a partial hydrogen-borrowing reaction that allows water and dihydrogen to be released as by-products.

\section{RESULTS AND DISCUSSION}

The full reaction mechanism for the formation of substituted acrylonitriles from the coupling of alcohols with nitriles is depicted in Figure 2, starting from the well-characterized catalyst 1.

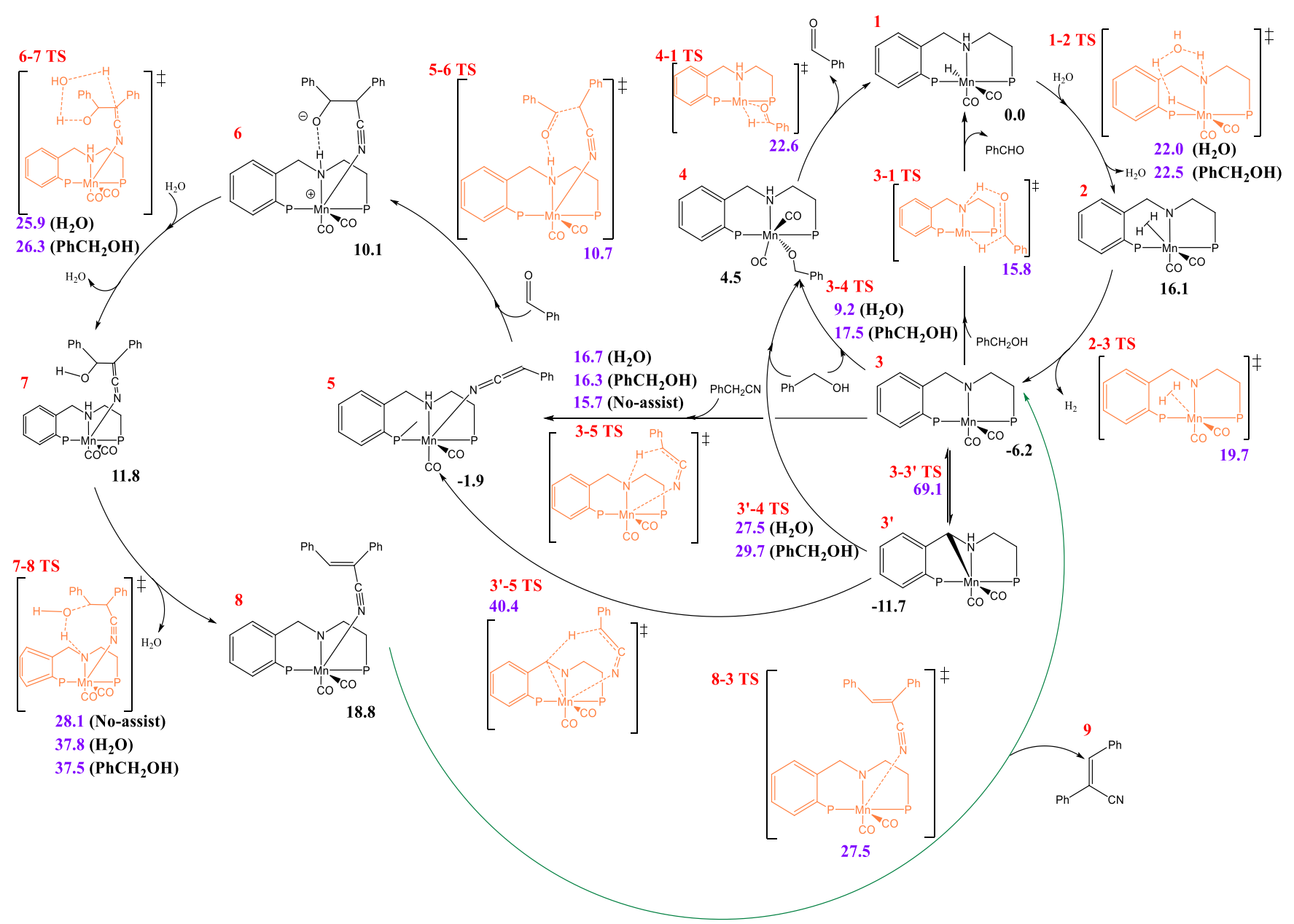

Figure 2. Full mechanism for the acceptorless dehydrogenative coupling of benzyl alcohols with nitriles (relative Gibbs energies for solvent media in $\mathrm{kcal} / \mathrm{mol}$ and referred to catalyst $\mathbf{1}$, and $\mathrm{P}=\mathrm{Pi}^{\mathrm{P}} \mathrm{Pr}_{2}$ ). For the sake of clarity, we have reported the missing Lewis structures for a few transition states in Figure 3 . All data shown were calculated at $\mathrm{T}=135^{\circ} \mathrm{C}$, mimicking the experiments. 
In the first step, $\mathrm{a} \mathrm{H}_{2}$ molecule is formed with a relatively low energy barrier (22.0 kcal/mol). A water molecule assists the $\mathrm{H}$ $\mathrm{H}$ bond formation from the hydride of the manganese and the hydrogen atom held by one of the $\mathrm{N}-\mathrm{H}$ groups of the catalyst. The resulting $\mathrm{H}_{2}$ coordination gives intermediate 2, which is unstable by $16.1 \mathrm{kcal} / \mathrm{mol}$ in comparison to $\mathbf{1}$. The rather low thermodynamic stability of $\mathbf{2}$ helps to understand the small energy barrier, only $3.6 \mathrm{kcal} / \mathrm{mol}$, required to release the $\mathrm{H}_{2}$ molecule and thus leading to the trigonal bipyramid 3. Therefore, $\mathbf{2}$ is the intermediate required for the formation of the hydrogen molecule and its liberation. In the experiments, an isomer of compound 3 was found, 3', which is $5.5 \mathrm{kcal} / \mathrm{mol}$ more stable, and so their equilibrium needed further discussion. In the previous work, ${ }^{14} 3$ ' was assigned as the thermodynamic isomer and $\mathbf{3}$ as the kinetic. Its interconversion involves a proton transfer to the nitrogen atom from its nearby methylene group in 3, to generate the $\mathrm{NH}$ and $\mathrm{CH}$ moieties in 3'. We found that the direct interconversion was unaffordable since it would require overcoming a $75.3 \mathrm{kcal} / \mathrm{mol}$ energy barrier. Moreover, adding a water molecule barely assisted this step as it only decreased the energy barrier by a mere 5.4 $\mathrm{kcal} / \mathrm{mol}$. Nonetheless, we had to consider that complex 3 ' had been determined using X-ray analysis, and that it had been obtained using two different approaches: firstly by heating the media up to $110^{\circ} \mathrm{C}$ for $30 \mathrm{~min}$, and, secondly, by leaving the media rest for $12 \mathrm{~h}$. This result implies that an alternative interconversion step, or sum of steps, had to be taken into account.

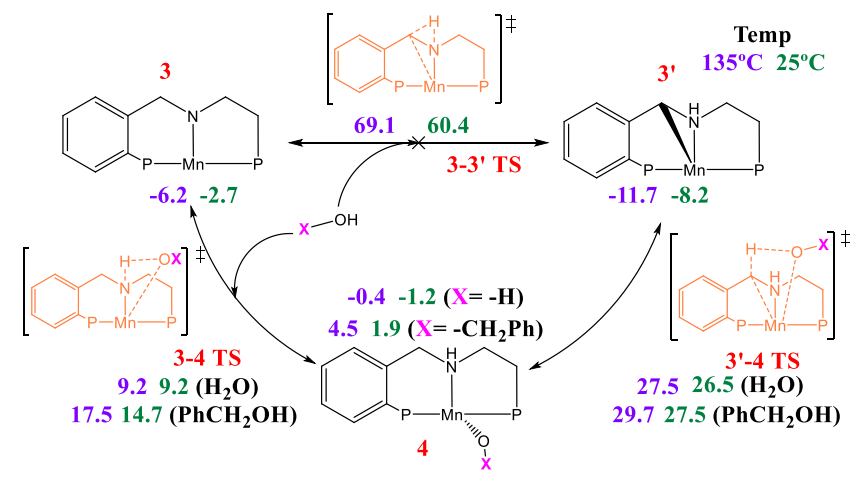

Figure 3. Formation of the thermodynamic isomer 3 ' from the kinetic 3, using either water or benzyl alcohol as a cocatalyst. Calculated at 25 and $135^{\circ} \mathrm{C}$ (energy values in green and violet, respectively) relative Gibbs energy values (in $\mathrm{kcal} / \mathrm{mol}$ ) referred to catalyst $1 ; \mathrm{P}=\mathrm{PiPr}_{2}$ and $\mathrm{CO}$ ligands not included for the sake of clarity).

Figure 3 depicts the steps involved in the interconversion between 3 and 3'. Results show that this interconversion takes place through complex 4 . The transformations of $3 \rightarrow 4$ and $4 \rightarrow 3$ ' assisted by an alcohol molecule have Gibbs energy barriers of 23.7 and $25.2 \mathrm{kcal} / \mathrm{mol}$, respectively, at $135^{\circ} \mathrm{C}$ (see Figure 3). Therefore, 3 and 3 ' can be interconverted using the alcohol in the media. Nevertheless, the experiments showed the formation of 3 ' from 3 without alcohol, but only stoichiometrically. ${ }^{14 a}$ Thus, the same approach using water was studied. As we hypothesized, when using water we obtained Gibbs energy barriers at $135^{\circ}{ }^{\circ} \mathrm{C}$ for the steps $3 \rightarrow 4$ and $4 \rightarrow 3$ ' of 15.4 and $27.9 \mathrm{kcal} / \mathrm{mol}$, respectively. These energy barriers are perfectly surmountable at room temperature and could easily be sped up by heating. These results are in perfect agreement with the experiments carried out at 25 and $135^{\circ} \mathrm{C}$, respectively. ${ }^{14}$

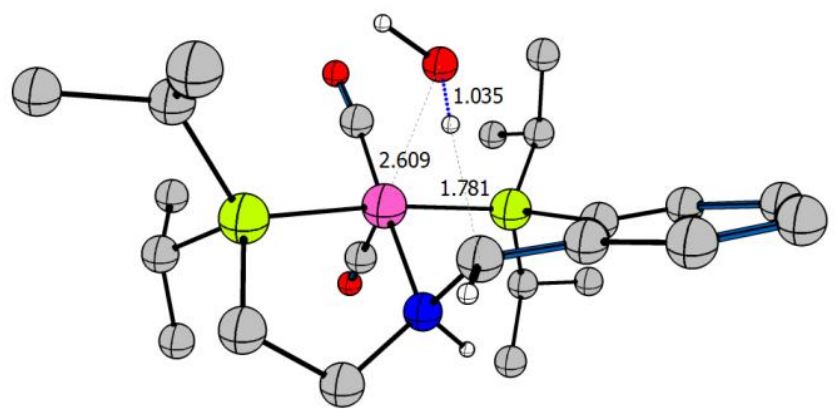

Figure 4. Structural geometry of the transition state for the step $\mathbf{4} \rightarrow \mathbf{3}$ ', assisted by water, with relevant distances shown in $\AA$ (most of the $\mathrm{H}$ atoms have been omitted for clarity).

The interconversion of $\mathbf{3} \rightarrow \mathbf{3}$ ' via intermediate 4 would indeed be feasible with traces of water from a non-dried solvent, acting as a proton transfer shuttle, ${ }^{16}$ progressing in the equilibria towards the thermodynamically most stable isomer 3 ' as Milstein et al. previously described. ${ }^{14}$ Additionally, we also studied the possibility of the interconversion between $\mathrm{OH}$ and $-\mathrm{OCH}_{2} \mathrm{Ph}$ ligands in molecule 4 to see whether they were interchangeable. With a barrier of 18.0 and $21.5 \mathrm{kcal} / \mathrm{mol}$ at 25 and $135^{\circ} \mathrm{C}$, respectively, to exchange the alkoxy ligand from the original alcohol by a hydroxo from a water molecule, we conclude that it is possible to exchange both ligands.

With regard to Figure 2, to close the catalytic cycle through 4, the liberation of the aldehyde requires overcoming a transition state (TS) with an energy barrier placed 18.1 $\mathrm{kcal} / \mathrm{mol}$ above $\mathbf{4}$. $4 \rightarrow \mathbf{1}$ involves a proton transfer from the methylene group of the alkoxy ligand still bonded to the metal, to release the aldehyde together with the regeneration of the catalyst $\mathbf{1}$. Thus, this is an inner shell process since the alkoxy group is bonded via its oxygen to the manganese making a single molecule. It is important to remark that we were not able to find a TS with an assisting water or alcohol molecule for this $\mathbf{4} \rightarrow \mathbf{1}$ transformation, probably due to the steric constraints of the active site.

The alternative outer shell mechanism is represented in the step $3 \rightarrow \mathbf{1}$ with an energy barrier of $22.0 \mathrm{kcal} / \mathrm{mol}$ above 3 and $27.5 \mathrm{kcal} / \mathrm{mol}$ with respect to 3'. In this process, the alcohol undertakes a concerted double proton transfer to yield the expected aldehyde in a single step. ${ }^{17}$ Comparing the mechanisms, both are possible but the outer shell mechanism is favored. We also considered the transition from 3' to $\mathbf{1}$ but with a barrier of $44.3 \mathrm{kcal} / \mathrm{mol}$ above 3', this step is not competitive.

Continuing along the acrylonitrile catalytic pathway from 3, the reaction can also evolve to intermediate 5 , since the corresponding transition state is $21.9 \mathrm{kcal} / \mathrm{mol}$ above 3 , and thus in perfect competition with $\mathbf{3} \rightarrow \mathbf{1}$ transformation, which step is only $0.1 \mathrm{kcal} / \mathrm{mol}$ higher in energy. The path from 3' to 5 was also studied. This transformation has a $52.2 \mathrm{kcal} / \mathrm{mol}$ energy barrier above 3', which is too high to be surpassed at 
experimental conditions. The addition of a nitrile to 3 was analyzed, connecting $\mathrm{Mn}$ with the $\mathrm{C}$ atom in the $\mathrm{CH}$ group of the nitrile or with the $\mathrm{N}$ atom. None of the attempts to connect $\mathrm{Mn}$ with the $\mathrm{C}$ atom of the $\mathrm{CH}$ group resulted in the formation of stable intermediates. On the other hand, the interaction of the nitrile through the $\mathrm{N}$ atom leads to intermediate 5. An alternative intermediate 5 , described in a similar way as species 5' in Scheme 3, would lead to a nitrile ligand anion and a protonated catalyst cation which would stay together through an electrostatic interaction, but calculations have confirmed the covalent character of the Mn$\mathrm{N}$ interaction in intermediate 5. Moreover, the Mayer bond order $^{18}(\mathrm{MBO})$ of the formed $\mathrm{Mn}-\mathrm{N}$ bond in complex 5 was found to be 0.55 , not far from the typical values of Mn-N bonds. ${ }^{19}$ Further, to check whether we had an ionic or a covalent bond, we analyzed the NPA charges of both moieties which were -0.25 (nitrile) and $0.25 \mathrm{e}^{-}$(Mn complex), thus far away from the ca. +1 and -1 charges expected in an ionic complex. The values of the charges and bond order support the covalency of this bond and rule out the ionic nature of the $\mathrm{Mn}-\mathrm{N}$ bond in complex 5 .

Once we reach molecule 5, given the nucleophilic character of the nitrile ligand, the reaction pathway evolves to $\mathbf{6}$ with the formation of the $\mathrm{C}-\mathrm{C}$ bond between the carbonyl of the aldehyde and the terminal $\mathrm{CHPh}$ moiety of the former nitrile. Intermediate $\mathbf{6}$ holds a favorable $\mathrm{H}$-bond between the $\mathrm{NH}$ moiety and the oxygen of the carbonyl group. On the other hand, the relatively low negative charge on the oxygen atom $\left(-0.402 \mathrm{e}^{-}\right)$of intermediate 6 is consistent with a partial anionic character on it. Moreover, the new $\mathrm{C}-\mathrm{C}$ bond is still rather weak, elongated by $1.748 \AA$, with an associated MBO of just $0.669 \mathrm{e}^{-}$. We also tried to approach the $\mathrm{C}-\mathrm{C}$ bond formation starting from 4 and adding the nitrile here, but without success.

The Gibbs energy barrier for the next step $6 \rightarrow 7$ at 15.8 $\mathrm{kcal} / \mathrm{mol}$ above $\mathbf{6}$ using water as a proton transfer assistant (32.9 $\mathrm{kcal} / \mathrm{mol}$ without $\mathrm{H}_{2} \mathrm{O}$ or alcohol as proton shuttle). The formation of intermediate 8 from $\mathbf{7}$, which consists of a concerted release of a water molecule through a condensation reaction, requires overcoming a $16.3 \mathrm{kcal} / \mathrm{mol}$ energy barrier. We also investigated if additional explicit water or alcohol molecules could play an assisting role in all the different proton transfer reactions present in the mechanism. An addition of a second water molecule in all the water assisted steps did not decrease any energy barrier. The substitution of the assisting water molecule by an assisting alcohol molecule increased the energy barriers by an small amount. In the presence of alcohol all assisted steps are still possible and therefore, the mechanism could be performed initially in a thoroughly dried media.

Finally, the regeneration of 3 and the release of the desired product 9 , closing the mechanistic cycle $(8 \rightarrow 3)$, occurs with an $8.7 \mathrm{kcal} / \mathrm{mol}$ barrier.

All in all, and considering the higher stability of molecule 3', we observe that the rate determining step (rds) is located at the Knoevenagel condensation step $\mathbf{7} \rightarrow \mathbf{8}$ involving release of water and formation of the acrylonitrile product $\mathbf{9}$ coordinated to Mn. This $\mathbf{7} \rightarrow \mathbf{8}$ process has a global energy barrier of $39.8 \mathrm{kcal} / \mathrm{mol}$ from 3', or $34.3 \mathrm{kcal} / \mathrm{mol}$ from 3. It is also important to note that the Gibbs energy barriers for steps $3 \rightarrow \mathbf{4}$ and $8 \rightarrow 3$ (both placed $39.2 \mathrm{kcal} / \mathrm{mol}$ above 3') have a difference of only $0.6 \mathrm{kcal} / \mathrm{mol}$ as compared to that of the rds, being the latter processes in clear competition with the described rds. ${ }^{20}$

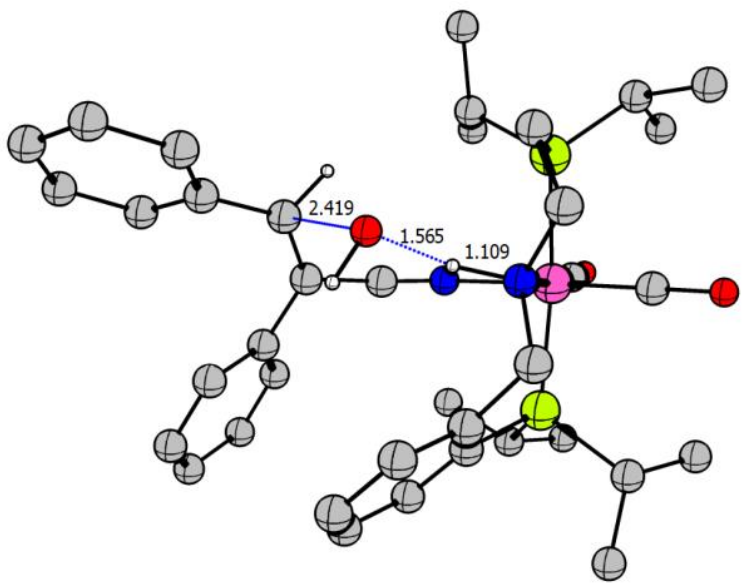

Figure 5. Structural geometry of the transition state that corresponds to the rds step $\mathbf{7} \rightarrow \mathbf{8}$, with relevant distances shown in $\AA$. Most of the $\mathrm{H}$ atoms have been omitted for clarity.

\section{CONCLUSIONS}

We have described the full DFT mechanism for the Mn catalyzed acceptorless dehydrogenative coupling of alcohols with nitriles. Our study indicates that the rate-determining step corresponds to the release of a water molecule that leads to the final product $\mathbf{9}(\mathbf{7} \rightarrow \mathbf{8} \mathrm{step})$. For the equilibrium between 3 and 3', our results show the importance that a water molecule has in assisting the proton transfer to carry out the interconversion between the kinetic complex 3 and its thermodynamic isomer 3'. The alcohol reagent can also adopt the same role, with an additional kinetic cost of only a few $\mathrm{kcal} / \mathrm{mol}$. We tested the coordination of the nitrile through the $\mathrm{C}$ atom alpha to the $\mathrm{N}$ atom in complex 3, but only the $\mathrm{N}$ coordination leads to the stable complex $\mathbf{5}$. Complex $\mathbf{5}$ was found to have the $\mathrm{Mn}$ metal center bonded covalently to the $\mathrm{N}$ atom of the nitrile ligand. A proton transfer assistant, like water, is needed in almost all proton transfer reactions except for the rds $\mathbf{7} \rightarrow \mathbf{8}$, and the $\mathbf{3} \rightarrow \mathbf{5}$ step. The reagent alcohol is also capable of undertaking the same proton transfer assistant role as water, although water performs better. It is worth emphasizing that the cooperative MnNH framework acts as both a platform for alcohol dehydrogenation and as a kind of templating agent for the Knoevenagel intramolecular proton relay and $\mathrm{H}$-bonding group. Finally, we confirmed that the catalytic mechanism is restarted when intermediate $\mathbf{8}$ released product $\mathbf{9}$ and yielded complex 3.

\section{- COMPUTATIONAL DETAILS}

DFT calculations were performed with the Gausianog set of programs, ${ }^{21}$ using the BP86 functional of Becke and Perdew, 22,23,24 together with the Grimme $\mathrm{D}_{3}(\mathrm{BJ})^{\mathbf{2 5 , 2 6}}$ correction term to the electronic energy. We described the electronic configuration of the molecular systems with the triple- $\zeta$ basis 
set of Weigend and Ahlrichs for all atoms (TZVP keyword in Gaussian). ${ }^{27}$ We performed the geometry optimizations without symmetry constraints, and analytical frequency calculations were carried out to characterize the located stationary points. These frequencies were used to calculate unscaled zero-point energies (ZPEs) as well as thermal corrections and entropy effects at 25 and 135 o $C$. Single-point energy calculations were performed on the optimized geometries with the Mo6 functional ${ }^{28}$ and the cc-pVTZ basis set. ${ }^{29}$ The same functional and basis set were used to estimate solvent effects with the universal solvation model SMD of Cramer and Truhlar, $3^{\circ}$ using toluene as the solvent. The reported Gibbs energies in this work include Mo6/cc-pVTZ//BP86-D3BJ/TZVP electronic energies with solvent effects obtained at the same level of theory, corrected with zero-point energies, thermal corrections and entropy effects evaluated at 25 or $135^{\circ} \mathrm{C}$ with the BP86-D3BJ/TZVP method.

\section{ASSOCIATED CONTENT}

\section{Supporting Information}

Computational details and all XYZ coordinates, energies and $3 \mathrm{D}$ structures of all species. This material is available free of charge via the Internet at http://pubs.acs.org.

\section{AUTHOR INFORMATION}

\section{REFERENCES}

(1) Zhu, C.-Z.; Wei, Y.; Shi, M. Base-Promoted Tandem Cyclization for the synthesis of Benzonitriles by C-C Bond Construction. Adv. Synth. Catal. 2018, 360, 808-813.

(2) Guchhait, S. K. Sisodiya, S.; Saini, M.; Shah, Y. V.; Kumar, G.; Daniel, D. P.; Hura, N.; Chaudhary, V. Synthesis of Polyfunctionalized Pyrroles via a Tandem Reaction of Michael Addition and Intramolecular Cyanide-Mediated Nitrile-to-Nitrile Condensation. J. Org. Chem. 2018, 83, 5807-5815.

(3) Sharma, K.; Shrivastava, A.; Mehra, R. N.; Deora, G. S.; Alam, M. M.; Zaman, M. S.; Akhter, M. Synthesis of Novel Benzimidazole Acrylonitriles for Inhibition of Plasmodium Falciparum Growth by Dual Target Inhibition. Arch. Pharm. Chem. Life Sci. 2018, 351:e1700251, 1-13.

(4) Hanna, T. A. The Role of Bismuth in the SOHIO Process. Coord. Chem. Rev. 2004, 248, 429-440.

(5) Knoevenagel, E. Condensation von Malondiure mit Aromatiachen Aldehyden durch Ammoniak und Amine. Ber. Dtsch. Chem. Ges. 1898, 31, 2596-2619.

(6) (a) Lidström, P.; Tierney, J.; Wathey, B.; Westman, J. Microwave Assisted Organic Synthesis - A Review. Tetrahedron 2001, 57, 9225-9283. (b) Greaves, T. L.; Drummond, C. J. Protic Ionic Liquids: Properties and Applications. Chem. Rev. 2oo8, 108, 206-237. (c) Hasegawa, S.; Horike, S.; Matsuda, R.; Furukawa, S.; Mochizuki, K.; Kinoshita, Y.; Kitagawa, S. ThreeDimensional porous Coordination Polymer Functionalized

\section{Corresponding Author}

*albert.poater@udg.edu,miquel.sola@udg.edu, david.milstein@weizmann.ac.il

ORCID

Jesús Antonio Luque Urrutia: oooo-0oo2-4695-5676

Miquel Solà: oooo-0oo2-1917-7450

David Milstein: 00oo-0002-2320-0262

Albert Poater: oooo-0oo2-8997-2599

\section{ACKNOWLEDGMENT}

J.A.L.U. thanks the Universitat de Girona for the IFUdG2017 PhD fellowship. A.P. and M.S. are grateful to the Ministerio de Economía y Competitividad (MINECO) of Spain (projects CTQ2014-59832-JIN and CTQ2017-85341-P), the Generalitat de Catalunya (project 2017SGR39, Xarxa de Referència en Química Teòrica i Computacional, the ICREA Academia prize 2014 awarded to M.S.), and the European Fund for Regional Development (FEDER) grant UNGI10-4E-801. D.M. thanks the European Research Council (ERC AdG 692775). D.M. holds the Israel Matz Professorial Chair. with Amide Groups Based on Tridentate Ligand: Selective Sorption and Catalysis. J. Am. Chem. Soc. 2007, 129, 2607-2614.

(7) (a) Grasselli, R. K.; Trifirò, F. Acrylonitrile from Biomass: Still Far from Being a Sustainable Process. Top. Catal. 2o16, 59, 1651-1658. (b) Guerrero-Pérez, M. O.; Bañares, M. A. Metrics of Acrylonitrile: From Biomass vs. Petrochemical Route. Catal. Today 2015, 239, 25-30.

(8) Li, C.-J. Cross-Dehydrogenative Coupling (CDC): Exploring $\mathrm{C}-\mathrm{C}$ Bond Formations beyond Functional Group Transformations. Acc. Chem. Res. 2009, 42, 335-344.

(9) (a) Tsukada, N.; Hartwig, J. F. Intermolecular and Intramolecular, Platinum-Catalyzed, Acceptorless Dehydrogenative Coupling of Hydrosilanes with Aryl and Aliphatic Methyl C-H Bonds. J. Am. Chem. Soc. 2005, 14, 5022-5023. (b) Gunanathan, C.; Milstein, D. Metal-Ligand Cooperation by AromatizationDearomatization: A New Paradigm in Bond Activation and "Green" Catalysis. Acc. Chem. Res. 2011, 44, 588-602.

(10) Gunanathan, C.; Milstein, D. Applications of Acceptorless Dehydrogenation and Related Transformations in Chemical Synthesis. Science 2013, 341, 1229712.

(11) (a) Schlapbach, L.; Züttel, A. Hydrogen-Storage Materials for Mobile Applications. Nature 2oo1, 414, 353-358. (b) Huber, G. W.; Iborra, S.; Corma, A. Synthesis of Transportation Fuels from Biomass: Chemistry, Catalysts and Engineering. Chem. Rev. 2006, 106, 4044-4098.

(12) (a) Li, J.-J.; Liu, Y.-X.; Tang, W.-J.; Xue, D.; Li, C.-Q.; Xiao, J.-L.; Wang, C. Atmosphere-Controlled Chemoselectivity: 
Rhodium-Catalyzed Alkylation and Olefination of Alkylnitriles with Alcohols. Chem. Eur. J. 2017, 23, 14445-14449. (b) Qu, S.; Dang, Y.; Song, C.; Wen, M.; Huang, K.-W.; Wang, Z.X. Catalytic Mechanisms of Direct Pyrrole Synthesis via Dehydrogenative Coupling Mediated by PNP-Ir or PNN-Ru Pincer Complexes: Crucial Role of Proton-Transfer Shuttles in the PNP-Ir System. J. Am. Chem. Soc. 2014, 136, 4974-4991.

(13) (a) Filonenko, G. A.; van Putten, R.; Hensen, E. J. M.; Pidko, E. A. Catalytic (De)Hydrogenation Promoted by NonPrecious Metals - Co, Fe and Mn: Recent Advances in an Emerging Field. Chem. Soc. Rev. 2o18, 47, 1459-1483. (b) Kallmeier, F.; Kempe, R. Manganese Complexes for (De)Hydrogenation Catalysis: A Comparison to Cobalt and Iron Catalysts. Angew. Chem. Int. Ed. 2018, 57, 46-60.

(14) (a) Chakraborty, S.; Das, U. K.; Ben-David, Y.; Milstein, D. Manganese Catalyzed $\alpha$-Olefination of Nitriles by Primary Alcohols. J. Am. Chem. Soc. 2017, 139, 11710-11713. (b) Chakraborty, S.; Gellrich, U.; Diskin-Posner, Y.; Leitus, G.; Avram, L.; Milstein, D. Manganese-Catalyzed N-Formylation of Amines by Methanol Liberating H2: A Catalytic and Mechanistic Study. Angew. Chem. Int. Ed. 2017, 56, 4229-4233.

(15) Daw, P.; Ben-David, Y.; Milstein, D. Direct Synthesis of Benzimidazoles by Dehydrogenative Coupling of Aromatic Diamines and Alcohols Catalyzed by Cobalt. ACS Catal. 2017, 7, 7456-7460.

(16) Nguyen, D. H.; Trivelli, X.; Capet, F.; Paul, J.-F.; Dumeignil, F.; Gauvin, R. M. Manganese Pincer Complexes for the Base-Free, Acceptorless Dehydrogenative Coupling of Alcohols to Esters: Development, Scope, and Understanding. ACS Catal. 2017, 7, 2022-2032.

(17) Bauer, J. O.; Chakraborty, S.; Milstein, D. Manganese-Catalyzed Direct Deoxygenation of Primary Alcohols. ACS Catal. 2017, 7, 4462-4466.

(18) (a) Mayer, I. Charge, Bond Order and Valence in the Ab Initio SCF Theory. Chem. Phys. Lett. 1983, 97, 270-274. (b) Mayer, I. Bond Order and Valence: Relations to Mulliken's Population Analysis. Int. J. Quantum Chem. 1984, 26, 151-154. (c) Bridgemann, A. J.; Cavigliasso, G.; Ireland, L. R.; Rothery, J. The Mayer Bond Order as a Tool in Inorganic Chemistry. J. Chem. Soc., Dalton Trans. 2001, 2095-2108.

(19) (a) Chen, X.-L.; Zhang, Y.; Zhang, M.-Y.; Zeng, M.-H. Bond Order Analysis, Packing Ratio, and Electronic Structures of Two Structural Polymorphs Based on Manganese Complexes. Chin. J. Chem. 2o17, 35, 927-930. (b) Jurca, T.; Ouanounou, S.; Shih, W.-C.; Ong, T.-G.; Yap, G. P. A.; Korobkov, I.; Gorelesky, S.; Richeson, D. Structural and Electronic Trends for Five Coordinate $1^{\text {st }}$ Row Transition Metal Complexes: Mn(II) to Zn(II) Captured in a Bis(IminoPyridine) Framework. Dalton Trans. 2016, 45, 14327-14334.

(20) Kozuch, S.; Shaik, S. How to Conceptualize Catalytic Cycles? The Energetic Span Model. Acc. Chem. Res. 2011, 44, 101110.

(21) Gaussian 09, Revision E.o1, Frisch, M. J.; Trucks, G. W.; Schlegel, H. B.; Scuseria, G. E.; Robb, M. A.; Cheeseman, J. R.;
Scalmani, G.; Barone, V.; Mennucci, B.; Petersson, G. A.; Nakatsuji, H.; Caricato, M.; Li, X.; Hratchian, H. P.; Izmaylov, A. F.; Bloino, J.; Zheng, G.; Sonnenberg, J. L.; Hada, M.; Ehara, M.; Toyota, K.; Fukuda, R.; Hasegawa, J.; Ishida, M.; Nakajima, T.; Honda, Y.; Kitao, O.; Nakai, H.; Vreven, T.; Montgomery, J. A., Jr.; Peralta, J. E.; Ogliaro, F.; Bearpark, M.; Heyd, J. J.; Brothers, E.; Kudin, K. N.; Staroverov, V. N.; Kobayashi, R.; Normand, J.; Raghavachari, K.; Rendell, A.; Burant, J. C.; Iyengar, S. S.; Tomasi, J.; Cossi, M.; Rega, N.; Millam, N. J.; Klene, M.; Knox, J. E.; Cross, J. B.; Bakken, V.; Adamo, C.; Jaramillo, J.; Gomperts, R.; Stratmann, R. E.; Yazyev, O.; Austin, A. J.; Cammi, R.; Pomelli, C.; Ochterski, J. W.; Martin, R. L.; Morokuma, K.; Zakrzewski, V. G.; Voth, G. A.; Salvador, P.; Dannenberg, J. J.; Dapprich, S.; Daniels, A. D.; Farkas, Ö.; Foresman, J. B.; Ortiz, J. V.; Cioslowski, J.; Fox, D. J. Gaussian, Inc., Wallingford CT, 2009.

(22) Becke, A. Density-Functional Exchange-Energy Approximation with Correct Asymptotic Behaviour. Phys. Rev. A 1988, 38, 3098-3100.

(23) Perdew, J. P. Density-Functional Approximation for the Correlation Energy of the Inhomogeneous Electron Gas. Phys. Rev. $B$ 1986, 33, 8822-8824.

(24) Perdew, J. P. Erratum: Density-functional Approximation for the Correlation Energy of the Inhomogeneous Electron Gas. Phys. Rev. B 1986, 34, 7406-7406.

(25) Johnson, E. R.; Becke, A. D. A Post-Hartree-Fock Model of Intermolecular Interactions: Inclusion of Higher-Order Corrections. J. Chem. Phys. 2006, 124, 174104-174113.

(26) (a) Grimme, S.; Antony, J.; Ehrlich, S.; Krieg, H. A Consistent and Accurate Ab Initio Parametrization of Density Functional Dispersion Correction (DFT-D) for the 94 Elements H-Pu. J. Chem. Phys. 2010, 132, 154104. (b) Grimme, S.; Ehrlich, S.; Goerigk, L. Effect of the Damping Function in Dispersion Corrected Density Functional Theory. J. Comput. Chem. 2011, 32, 1456-1465.

(27) Weigend, F.; Ahlrichs, R. Balanced Basis Sets of Split Valence, Triple Zeta Valence and Quadruple Zeta Valence Quality for $\mathrm{H}$ to $\mathrm{Rn}$ : Design and Assessment of Accuracy. Phys. Chem. Chem. Phys. 2005, 7, 3297-3305.

(28) Zhao, Y.; Truhlar, D. G. The Mo6 Suite of Density Functionals for Main Group Thermochemistry, Thermochemical Kinetics, Noncovalent Interactions, Excited States, and Transition Elements: Two New Functionals and Systematic Testing of Four Mo6-Class Functionals and 12 Other Functionals. Theor. Chem. Acc. 2008, 120, 215-241.

(29) Kendall, R. A.; Dunning Jr., T. H.; Harrison, R. J. Electron Affinities of the First-Row Atoms Revisited. Systematic Basis Sets and Wave Functions. J. Chem. Phys. 1992, 96, 6796-6806.

(30) Marenich, A. V.; Cramer, C. J.; Truhlar, D. G. Universal Solvation Model Based on Solute Electron Density and a Continuum Model of the Solvent Defined by the Bulk Dielectric Constant and Atomic Surface Tensions. J. Phys. Chem. B 2oog, $113,6378-6396$. 